\title{
Life Expectancy and Healthy Life Expectancy of Adults in Oman: Does Women's Longer Life Expectancy than Men Mean Success or Burden for Women?
}

\author{
M. Mazharul Islam
}

Department of Statistics, Sultan Qaboos University, P.O Box 36, Post Code 123, Muscat, Oman

\begin{abstract}
Objectives: The objective of this study was to examine the life expectancy (LE) and healthy life expectancy (HLE) of Omani adults with age and gender differentials, focusing on whether the higher LE of women than men is a gain or burden for women.

Method: Data for the study come from multiple sources such as the 2010 population census, the 2008 World Health Survey in Oman, and secondary data published in the Statistical Yearbook of Oman. The life table and the modified life table proposed by Sullivan were used for estimating the LE and HLE of adult people of age 20 and above, respectively.

Results: LE in Oman reached 76 years for both sexes in recent times. However, since 2010 LE has been stalled in the vicinity of 76 years in Oman. Women had higher LE than men (79 years versus 74 years). In terms of HLE, men outweighed women in Oman. At the age of 20, the gap between male-female LE was found to be 4.7 years in favor of females, whereas the gap between male-female HLE was found to be 5.8 years in favor of males. Females spent a relatively long time in poor health status than males (20.8 years versus 10.8 years) and the proportion of life spent in poor health was greater for females than males (35.0\% vs. $19.3 \%)$. This revealed the paradox of less mortality but higher morbidity among women, supporting the "Failure of Success" hypothesis.
\end{abstract}

Conclusion: Appropriate health policy and strategy need to be taken to reduce the gender gap in LE and HLE in Oman.

Keywords: Life expectancy, Healthy life expectancy, Burden, Morbidity, Oman.

\section{INTRODUCTION}

The $20^{\text {th }}$ century has been a period of both demographic and epidemiologic transitions for the populations in both developed and developing countries [1, 2]. During this period, almost all the countries across the world experienced a huge decline in mortality and fertility, resulting in one of the remarkable public health achievements of the twentieth century the impressive gain in average life expectancy (LE) - the average remaining years an individual of a particular age can be expected to live. For example, in the United States, the average life expectancy has increased from 47.3 years in 1900 to 76.8 years in 2000 , a gain of about 30 years [3]. Most of the gain in LE came from controlling infectious diseases, improving public health, and economic progress [4]. The decline in mortality and fertility over the period and the increase in longevity, combined with the increase of degenerative chronic diseases, caused a rapid process of demographic and epidemiologic transition, imposing a new phenomenon of global population aging and public health agenda in the face of the complexity of the new morbidity pattern $[1,5]$.

The substantial gain in LE over the period caused a dramatic change in the age structures of the

*Address correspondence to this author at the Department of Statistics, Sultan Qaboos University, P.O Box 36, Post Code 123, Muscat, Oman;

E-mail: mmazhar.islam@yahoo.com populations, giving a sharp rise in the percent of the elderly population. There was also a sharp rise in noncommunicable chronic and degenerative diseases, primarily affecting the older population [6]. The significant gain in average LE and its demographic and health consequences lead to a question of what quality of life may be experienced in the extra years lived. Are people living longer in healthy conditions or living relatively with a greater burden of morbidity in the older ages? Gruenberg [7] and Kramer [8] argued that an increase in the average LE was merely a result of a prolonged period living with disability and disease. Gruenberg [7] termed it as Failure of Success. As Olshansky et al. [9] observed that the advances in medical technology improve the survival of those with a disabling condition on one hand and the declining mortality from fatal diseases leads to a shift in the distribution of causes of disability from fatal to nonfatal diseases of aging on the other. It is also suggested that the increase in longevity of life would result in a compression of morbidity to the later years of life [10]. However, empirical findings do not support the existence of compression of morbidity when it is defined as major diseases and mobility functioning loss [11]. Riley and Alter [12] have demonstrated, using historical data sources, that morbidity levels tend to rise after mortality declines, rather than the reverse. All these observations encouraged researchers and policymakers to pay attention more to preventing 
disability and morbidity, improving functional healthy life, and developing a population health measure incorporating both longevity and morbidity. One such measure that includes both of these components is broadly known as "healthy life expectancy" (HLE) - a measure of population health that combines length and quality of life into a single measure. While LE is simply the average number of years which a person may be expected to spend alive, HLE is the average number of years which they are expected to spend in a state of good health.

The concept of health expectancy as a health indicator has been developed in the 1960s in the US [13]. After that Sullivan [14] developed a simple method for calculating HLE based on the life table model, which is now widely used as an indicator of the population health measure. According to the World Health Organization [15], HLE's potential applications include comparing the health of one population with another, monitoring changes in the health of populations, and identifying and quantifying health inequalities within populations. Health expectancy can be computed by a variety of different health dimensions. Empirical studies estimated healthy life expectancy indexes based on a variety of health attributes $[16,17]$. When health states are measured based on self-reported health (SRH) status, the more general name "healthy years" or "healthy life expectancy" is used. However, when health states are defined based on social or functional limitations, the estimated index is called "disability-free life expectancy." When health states are measured by activity limitation, the index is often called "active life expectancy" [6].

Sultanate of Oman, an oil-rich high-income country of the Arabian Peninsula, is passing through a crucial phase of demographic, epidemiological, and health transition [18]. About 4.5 million people live within a land area of $309,500 \mathrm{sq}$. km. Along with socioeconomic improvement; there is an impressive improvement in the health and survival of the people of the country, which is reflected in the substantial increase in LE in Oman over the last several decades [18]. LE in Oman has increased from a very low average of 36 years in 1950 to 76 years in 2020, and women outweighed men at LE in Oman [19]. Many studies have shown that women live longer than men at all ages, but spend a higher proportion of their total LE in poorer health, a phenomenon described as the "male-female health-survival paradox" or the "gender paradox in health and mortality"[20 - 22]. It is, therefore, important to know whether this gain in the life of Omani people is also associated with long healthy life or longer burdensome life. The higher LE among women than men also raised the question: do women have a better quality of life or healthy life than men in the country? However, to our knowledge, there is no study in Oman on this issue. Thus, the objective of this study was to examine the LE and HLE of the adult people and their differentials by age and gender. The study also examined whether the higher LE of women than men is a gain or burden (Failures of Success) for adult women in Oman.

\section{MATERIALS AND METHODS}

\section{Source of Data}

Data for the study come from multiple sources such as the 2010 population census, the 2008 World Health Survey in Oman, and secondary data published in the Statistical Yearbook of Oman. This paper analyzed HLE in Oman using the Sullivan technique. The information necessary for applying the Sullivan technique are (1) population and deaths or age-specific mortality rates that permit the construction of a life table, and (2) prevalence of health states according to age. In the present study, mortality and population data were obtained from the 2010 Population and Housing Census in Oman. The morbidity information used in applying the Sullivan method comes from the 2008 Oman World Health Survey (OWHS). We assumed that the mortality situation in 2008 was the same as in 2010.

The 2008 OWHS was implemented by the Ministry of Health of Oman in collaboration and technical support of the World Health Organization (WHO). It was a part of the World Health Survey (WHS) series which was developed by the WHO as a means to collect comprehensive baseline information on the health of populations in different countries across the world. The target population of the 2008 OWHS was the adult population of age 18 and above irrespective of their marital status and nationality. Data were collected by face-to-face interview technique and structured questionnaires developed by the $\mathrm{WHO}$ for WHS after extensive pre-testing and standardization. The details of the methodology of the OWHS have been published elsewhere [23]. Administratively Oman is divided into 10 regions. Each region has an urban and rural place of residence. A multi-stage stratified cluster sampling design was employed to select a sample of about 5000 households from all over the country with 4.5 million people. Stratification was made 
on two factors; level of urbanization (urban/rural) and geographical distribution. The sample size was calculated to ensure adequate precision, and to allow hypothesis testing ensuring adequate power. Out of 4,717 successful individuals interviewed in the survey, $3,370(71 \%)$ were Omani nationals and the rest of $1,347(29 \%)$ were non-Omani. In this study, we have considered Omani nationals of age 20 and above as our study population. To characterize the general health status, a single-item self-rated health (SRH) status has been used. In the survey, respondents were asked to rate their health status on the day of the interview from very good, 'good', 'moderate', 'bad' or 'very bad'. However, for analytical purposes and simplified the analysis, we breakdown the responses into two categories by combing the categories 'very good' and 'good' into one category of 'good' health status and the categories 'moderate', 'bad' or 'very bad' into one category of 'poor' health status.

\section{Calculation of LE}

The life table, also known as the mortality table, provides the most complete statistical description of the mortality situation of a population. Demographers also use life tables for a variety of other demographic and statistical analyses. The LE can be estimated by constructing the ordinary life table. We have constructed an ordinary abridge period life table for the adult population of age 20 and above following Chiang [24] method. The life table usually has the following column and functions:

Table 1: Life Table for Adult Omani Population, 2010
Column 1: $(x, x+n)$ indicate ages in interval with width $n=5$ except for the final age which is open-ended and usually denoted by $\omega$.

Column 2: ${ }_{n} m_{x}$, the death rate in age interval $(\mathrm{x}$, $\mathrm{x}+\mathrm{n})$, and is calculated by

$$
{ }_{n} m_{x}=\frac{{ }_{n} D_{x}}{{ }_{n} P_{x}}
$$

where ${ }_{n} D_{x}$ are deaths in the interval $(\mathrm{x}, \mathrm{x}+\mathrm{n})$ and ${ }_{n} P_{x}$ is the midyear population in the interval $(\mathrm{x}, \mathrm{x}+\mathrm{n})$. The ${ }_{n} P_{x}$ and ${ }_{n} D_{x}$ values are usually obtained from the population census, or national level survey, or vital registration system. In this study, these were obtained from the 2010 Population Census in Oman.

Column 3: ${ }_{n} \hat{q}_{x}$ is the probability of dying in the interval $(x, x+n)$, and is calculated from the value of ${ }_{n} m_{x}$ using the relation

${ }_{n} q_{x}=\frac{2 \times n \times{ }_{n} m_{x}}{2+n \times{ }_{n} m_{x}}$

Column 4: $l_{x}$, the number of persons who attain exact age $x$ out of the cohort of $l_{0}=100,000$ births, called the radix of the life table.

Column 5: ${ }_{n} d_{x}$, the number dying in the interval $(\mathrm{x}$, $\mathrm{x}+\mathrm{n})$. The interrelationships between $l_{x},{ }_{n} d_{x}$ and ${ }_{n} q_{x}$ are as follows:

\begin{tabular}{|c|c|c|c|c|c|c|c|c|c|}
\hline Age & ${ }_{n} P_{x}$ & ${ }_{n} D_{x}$ & ${ }_{n} m_{x}$ & ${ }_{n} q_{x}$ & $l_{x}$ & ${ }_{n} d_{x}$ & ${ }_{n} L_{x}$ & $T_{x}$ & $e_{x}$ \\
\hline $20-24$ & 240,492 & 218 & 0.000906 & 0.004522 & 100,000 & 452 & 498869 & 5818040 & 58.18 \\
\hline $25-29$ & 206,181 & 163 & 0.000791 & 0.003945 & 99,548 & 393 & 496757 & 5319170 & 53.43 \\
\hline $30-34$ & 152,842 & 131 & 0.000857 & 0.004276 & 99,155 & 424 & 494715 & 4822413 & 48.64 \\
\hline $35-39$ & 101,433 & 109 & 0.001075 & 0.005359 & 98,731 & 529 & 492333 & 4327698 & 43.83 \\
\hline $40-44$ & 73,014 & 132 & 0.001808 & 0.008999 & 98,202 & 884 & 488801 & 3835365 & 39.06 \\
\hline $45-49$ & 59,308 & 172 & 0.0029 & 0.014396 & 97,318 & 1401 & 483089 & 3346564 & 34.39 \\
\hline $50-54$ & 52,119 & 242 & 0.004643 & 0.02295 & 95,917 & 2201 & 474083 & 2863475 & 29.85 \\
\hline $55-59$ & 36,153 & 213 & 0.005892 & 0.029031 & 93,716 & 2721 & 461778 & 2389392 & 25.50 \\
\hline $60-64$ & 32,464 & 435 & 0.013399 & 0.064826 & 90,995 & 5899 & 440230 & 1927614 & 21.18 \\
\hline $65-69$ & 22,729 & 310 & 0.013639 & 0.065946 & 85,097 & 5612 & 411453 & 1487384 & 17.48 \\
\hline $70-74$ & 20,820 & 579 & 0.02781 & 0.13001 & 79,485 & 10334 & 371589 & 1075931 & 13.54 \\
\hline $75-79$ & 10,327 & 473 & 0.045802 & 0.205482 & 69,151 & 14209 & 310231 & 704341.5 & 10.19 \\
\hline $80-84$ & 8,046 & 497 & 0.06177 & 0.267535 & 54,942 & 14699 & 237961 & 394110.1 & 7.17 \\
\hline $85+$ & 6,759 & 704 & 0.104157 & 1.000000 & 40,243 & 40243 & 156149 & 156149 & 3.88 \\
\hline
\end{tabular}


${ }_{n} d_{x}=l_{x} \times{ }_{n} q_{x}, \mathrm{x}=0,1, \ldots \ldots \ldots, \omega$

and $l_{x+n}=l_{x}-{ }_{n} d_{x}, \mathrm{x}=0,1, \ldots \ldots \ldots, \omega-1$.

Also ${ }_{n} d_{x}=l_{x+n}-l_{x}, \mathrm{x}=0,1, \ldots \ldots \ldots, \omega-1$,

Column 6: ${ }_{n} L_{x}$ the number of person-years lived by the total cohort in the interval $(x, x+n)$, and ${ }_{n} L_{x}=\frac{n}{2}\left(l_{x}+l_{x+n}\right)$, for $\mathrm{x} \geq 1$, and $\mathrm{L}_{0}$ is calculated as $L_{0}=$ $0.3 I_{0}+0.7 I_{1}$. However, for the last age group (85+) an assumption was made about $\mathbf{e}_{85+}$ and then ${ }_{n} \mathrm{~L}_{85+}$ was calculated using the formula ${ }_{n} L_{85+}=I_{85+}{ }^{*} \mathbf{e}_{85+}[43]$.

Column 7: $T_{x}$, the total number of years lived beyond age $x$. Thus,

$T_{x}={ }_{n} L_{x}+{ }_{n} L_{x+n}+\ldots \ldots \ldots+L_{\omega}=\sum_{y=x}^{\omega} L_{y}, \mathrm{x}=0,1, \ldots \ldots \ldots, \omega$

and Column 8: $e_{x}$, the LE is estimated by $e_{x}=\frac{T_{x}}{l_{x}}$.

Thus, LE is the outcome of the life table which measures the average life expectancy of groups of people currently at specified ages if they lived the rest of their lives experiencing the age-specific mortality rates observed for the population at a specific time.

Using the mortality data obtained from the 2010 population and housing census in Oman, we constructed the national life table for the Omani adult population of age 20 and above as well as for male and female. As an illustrative example, Table 1 presents the life table for the Omani adult population of age 20 years and above.

\section{Calculation of HLE}

The HLE can be estimated by modifying the ordinary life table functions as suggested by Sullivan [14]. To calculate HLE, we first obtained the agespecific prevalence rates of being healthy, by calculating the rates of reporting "poor" health $\left({ }_{n} \pi_{x}\right)$. The rate of being healthy, that is, reporting "good" health is then $\left(1-{ }_{n} \pi_{x}\right)$. An example is shown in columns 4 and 5 of Table 2 . Then for each age interval $(x, x+n)$, the rates of being healthy $\left(1-{ }_{n} \pi_{x}\right)$ are multiplied with the total number of years lived within the same age interval $\left({ }_{n} L_{x}\right)$ to estimate the total number of years a group of persons is expected to live in a healthy state during the interval which we denoted by ${ }_{n} L_{x}^{h}$. Thus

${ }_{n} L_{x}^{h}=\left(1-{ }_{n} \pi_{x}\right) \times{ }_{n} L_{x}$

Thus the values of ${ }_{n} L_{x}^{h}$ are the number of healthy person-years lived in the interval $(x, x+n)$.

The number of healthy person-years lived beyond age $x$ is then obtained as

$T_{x}^{h}=\sum_{i=x}^{\omega}{ }_{n} L_{i}^{h}$

Finally, like in an ordinary life table, the HLE is obtained as

$e_{x}^{h}=\frac{T_{x}^{h}}{l_{x}}$

Table 2: Calculation of Healthy Life Expectancy (HLE) for Adult Omani Population, 2010

\begin{tabular}{|c|c|c|c|c|c|c|c|}
\hline Age & $l_{x}$ & ${ }_{n} L_{x}$ & ${ }_{n} \pi_{x}$ & $1_{1-} \pi_{x}$ & ${ }_{n} L_{x}^{h}$ & $T_{x}^{h}$ \\
\hline \hline $20-24$ & 100000 & 498869 & 0.099 & 0.901 & 449481 & 4416366 & 44.16 \\
\hline $25-29$ & 99548 & 496757 & 0.106 & 0.894 & 444101 & 3966885 & 39.85 \\
\hline $30-34$ & 99155 & 494715 & 0.101 & 0.899 & 444749 & 3522784 & 35.53 \\
\hline $35-39$ & 98731 & 492333 & 0.154 & 0.846 & 416513 & 3078035 & 31.18 \\
\hline $40-44$ & 98202 & 488801 & 0.169 & 0.831 & 406193 & 2661521 & 27.10 \\
\hline $45-49$ & 97318 & 483089 & 0.194 & 0.806 & 389370 & 2255328 & 23.17 \\
\hline $50-54$ & 95917 & 474083 & 0.272 & 0.728 & 345133 & 1865958 & 19.45 \\
\hline $55-59$ & 93716 & 461778 & 0.31 & 0.69 & 318627 & 1520826 & 16.23 \\
\hline $60-64$ & 90995 & 440230 & 0.289 & 0.711 & 313003 & 1202198 & 13.21 \\
\hline $65-69$ & 85097 & 411453 & 0.35 & 0.65 & 267445 & 889195 & 10.45 \\
\hline $70-74$ & 79485 & 371589 & 0.374 & 0.626 & 232615 & 621750 & 7.82 \\
\hline $75-79$ & 69151 & 310231 & 0.425 & 0.575 & 178383 & 389136 & 5.63 \\
\hline $80-84$ & 54942 & 237961 & 0.449 & 0.551 & 131117 & 210753 & 3.84 \\
\hline $85+$ & 40243 & 156149 & 0.49 & 0.51 & 79636 & 79636 & 1.98 \\
\hline
\end{tabular}


Table 3: Life Expectancy (LE) in Oman in Selective Recent Years by Gender, 1995-2020

\begin{tabular}{|c|c|c|c|}
\hline \multirow{2}{*}{ Year } & \multicolumn{3}{|c|}{ Life expectancy at birth } \\
\cline { 2 - 4 } & Male & Female & Both sex \\
\hline \hline 1995 & 66.8 & 67.7 & 73.4 \\
\hline 2000 & 72.5 & 74.3 & 74.3 \\
\hline 2005 & 73.2 & 75.4 & 76.1 \\
\hline 2010 & 73.6 & 78.7 & 76.4 \\
\hline 2015 & 74.2 & 78.8 & 78.6 \\
\hline
\end{tabular}

Source: Statistical Year Books, National Centre for Statistics and Information (NCSI), Ministry of National economy, Available at http: www.ncsi.gov.om

The expected years of unhealthy life are then obtained as $e_{x}-e_{x}^{h}$. As an illustrative example, Table 2 presents the calculation of HLE for Omani adult population of age 20 years and above by applying the Sullivan method, taking into consideration the proportion of individuals in each quinquennial age group with a self-rated health status that is good.

\section{RESULTS}

Table 3 shows the LE at birth in Oman for the period 1995-2020, which were obtained from the published Statistical Year-Books of the Ministry of National Economy of Oman [25]. The results indicate that the overall LE at birth for both males and females combined has reached 76 years in Oman in 2020. This may be interpreted as the average number of years a newborn is expected to live 76 years in Oman provided that the newborn experience the age-specific mortality rate of 2020. The LE at birth is higher for females than males (78.9 years vs. 73.6 years), and the male-female gap in LE is about 5 years. The results also indicate that since 2010, the total LE remains stable at 76 years. This is also true for both males and females.

Figure 1 depicts the historical trends in LE at birth in Oman since 1950 as documented by the World Population Prospects 2019 Revision of the United Nations (UN) [26]. Since 1950, there is a steady increase in LE at birth in Oman. LE has increased from 36 years in 1950 to 78 Years in 2020, which is more than doubled and about 117 percent increase within 70 years period. The UN projection results also indicate that the LE at birth in Oman will reach 80 years in 2030 [26]. Figure 1 also indicates that female has higher LE at birth than male, and over the period the gap between male and female is widening, reaching about 5 years gap between male and female in recent time.

In this study, the life table technique used to illustrate the Sullivan method's calculation has been

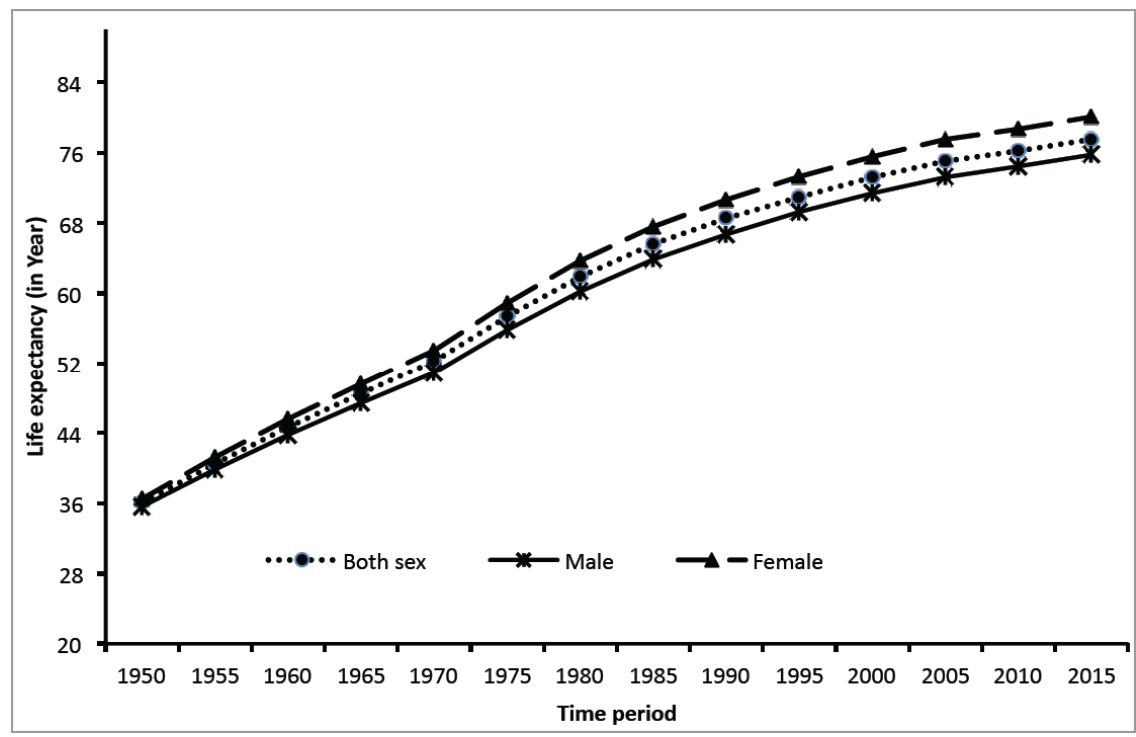

Figure 1: Historical trends in LE of Omani nationals by gender, $1950-2015$.

Source: UN Population Division: World Population Prospects: The 2019 Revision. 


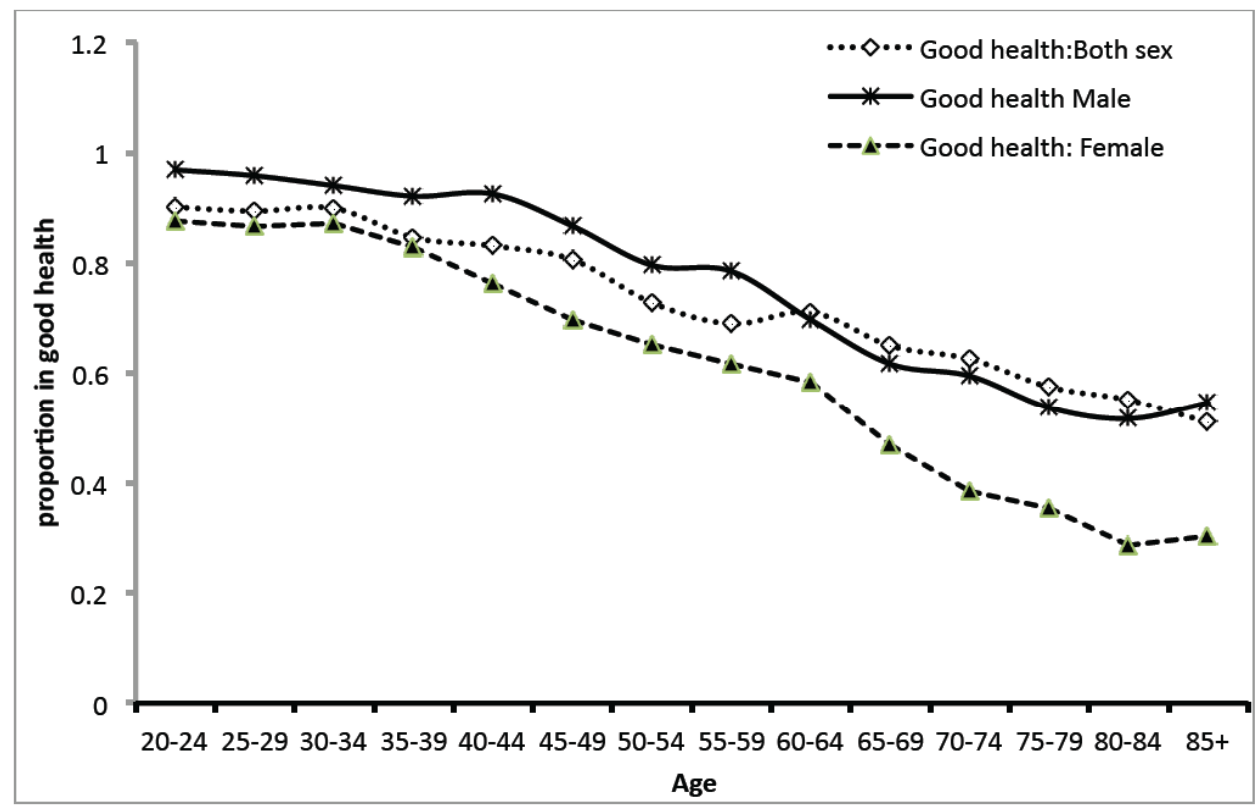

Figure 2: Age-specific proportion in good health by gender, 2008 WHS in Oman.

summarized in quinquennial age groups, beginning at 20 years of age, since the information from the World Health Survey (WHS) in Oman refers to individuals 18 years or older. Table 1 shows the application of the life table technique to illustrate the calculation of LE for a synthetic cohort of adult Omani people of age 20 years. The results indicate that the LE at age 20 was 58.2 years and the LE at age 65 years was 17.5 years.

Table 2 shows the application of the Sullivan method, taking into consideration the proportion of individuals in each quinquennial age group with selfrated health that is defined as good as the specific rate by age of being healthy. Column 5 of Table 2 shows the observed age-specific proportion of Omani people with good health. As expected the prevalence of good health decrease monotonically with age. However, as can be seen from Figure $\mathbf{2}$ that the age-specific prevalence of good health was higher among males than females.

Similar to the ordinary life table, the last column (column 8) of Table 2 presents the HLE $\left(e_{x}^{h}\right)$ for the Omani adults of age 20 and above. As can be observed from column 8 of Table 3 , at the age of twenty, one expects to live another 44.2 healthy years.

Table 4 displays the LE, HLE, number of years live in poor health state and the percentage of total LE live in poor health state by age and sex for Omani population. For example, at age 20 years, whereas the total LE was 58.2 years, the HLE was 44.2 years, and thus 14.0 years were lived in a poor state of health which accounts for $24 \%$ of the total LE at age 20 years. Similarly, at age 65 years, the total LE was 17.5 years, the HLE was 10.5 years, and consequently, 7.0 years were lived in a poor state of health which accounts for $40 \%$ of the total LE at age 65 years.

In terms of total LE, females outweigh males in all age groups. On average, females at age 20 expect to live approximately 5.0 years more than males of the same age (60.7 years versus 56.1 years). At the age of 65 years, the difference by sex is, on average, 3.0 years in favor of females. However, concerning the HLE, given that the prevalence of poor health is more pronounced among females, females have a lower average HLE compared to males. At age 20 years, whereas the HLE was found to be 45.3 years for males, the corresponding figure for females was 39.5 years, about 6 years in favor of males. Consequently, at age 20 years, males live 10.8 years in poor health status, as opposed to 20.8 years for females, accounting for $19.0 \%$ of the total LE at poor state among males compared to $35 \%$ among females. According to the estimate, at the age of 65 years, it is expected that males spend, on average, $42.0 \%$ of the years yet to be lived with poor health status. This average is $64.0 \%$ for females.

\section{DISCUSSIONS}

This study examined the level and trends of LE in Oman and estimated the HLE in Oman for adults of age 20 and above. LE and HLE are the two important measures of population health that are needed to 
Table 4: Life Expectancy (LE) and Healthy Life Expectancy (HLE) by Age and Gender

\begin{tabular}{|c|c|c|c|c|}
\hline & Life expectancy (LE) & $\begin{array}{l}\text { Healthy life expectancy } \\
\text { (HLE) }\end{array}$ & $\begin{array}{l}\text { Years lived in a poor } \\
\text { health state }\end{array}$ & $\begin{array}{c}\% \text { of total LE live in poor } \\
\text { health sate }\end{array}$ \\
\hline \multicolumn{5}{|l|}{ Both sex } \\
\hline $20-24$ & 58.18 & 44.16 & 14.02 & 24.10 \\
\hline $25-29$ & 53.43 & 39.85 & 13.58 & 25.42 \\
\hline $30-34$ & 48.64 & 35.53 & 13.11 & 26.95 \\
\hline $35-39$ & 43.83 & 31.18 & 12.65 & 28.86 \\
\hline $40-44$ & 39.06 & 27.10 & 11.96 & 30.62 \\
\hline $45-49$ & 34.39 & 23.17 & 11.22 & 32.63 \\
\hline $50-54$ & 29.85 & 19.45 & 10.4 & 34.84 \\
\hline $55-59$ & 25.50 & 16.23 & 9.27 & 36.35 \\
\hline $60-64$ & 21.18 & 13.21 & 7.97 & 37.63 \\
\hline $65-69$ & 17.48 & 10.45 & 7.03 & 40.22 \\
\hline $70-74$ & 13.54 & 7.82 & 5.72 & 42.25 \\
\hline $75-79$ & 10.19 & 5.63 & 4.56 & 44.75 \\
\hline $80-84$ & 7.17 & 3.84 & 3.33 & 46.44 \\
\hline $85+$ & 3.88 & 1.98 & 1.90 & 48.97 \\
\hline \multicolumn{5}{|l|}{ Male } \\
\hline $20-24$ & 56.05 & 45.26 & 10.79 & 19.25 \\
\hline $25-29$ & 51.40 & 40.70 & 10.7 & 20.82 \\
\hline $30-34$ & 46.69 & 36.14 & 10.55 & 22.60 \\
\hline $35-39$ & 41.95 & 31.64 & 10.31 & 24.58 \\
\hline $40-44$ & 37.24 & 27.25 & 9.99 & 26.83 \\
\hline $45-49$ & 32.68 & 22.94 & 9.74 & 29.80 \\
\hline $50-54$ & 28.24 & 18.99 & 9.25 & 32.75 \\
\hline $55-59$ & 24.00 & 15.51 & 8.49 & 35.38 \\
\hline $60-64$ & 19.90 & 12.15 & 7.75 & 38.94 \\
\hline $65-69$ & 16.49 & 9.62 & 6.87 & 41.66 \\
\hline $70-74$ & 12.78 & 7.28 & 5.5 & 43.04 \\
\hline $75-79$ & 9.42 & 5.23 & 4.19 & 44.48 \\
\hline $80-84$ & 6.25 & 3.29 & 2.96 & 47.36 \\
\hline $85+$ & 2.82 & 1.54 & 1.28 & 45.39 \\
\hline \multicolumn{5}{|l|}{ Female } \\
\hline $20-24$ & 60.74 & 39.46 & 21.28 & 35.03 \\
\hline $25-29$ & 55.88 & 35.17 & 20.71 & 37.06 \\
\hline $30-34$ & 50.99 & 30.91 & 20.08 & 39.38 \\
\hline $35-39$ & 46.11 & 26.62 & 19.49 & 42.26 \\
\hline $40-44$ & 41.27 & 22.51 & 18.75 & 45.44 \\
\hline $45-49$ & 36.48 & 18.81 & 17.67 & 48.43 \\
\hline $50-54$ & 31.84 & 15.51 & 16.33 & 51.29 \\
\hline $55-59$ & 27.38 & 12.50 & 14.88 & 54.33 \\
\hline $60-64$ & 22.86 & 9.43 & 13.43 & 58.75 \\
\hline $65-69$ & 18.82 & 6.89 & 11.93 & 63.39 \\
\hline $70-74$ & 14.61 & 4.83 & 9.78 & 66.96 \\
\hline $75-79$ & 11.27 & 3.43 & 7.84 & 69.55 \\
\hline $80-84$ & 8.48 & 2.87 & 5.62 & 66.20 \\
\hline $85+$ & 5.40 & 2.12 & 3.28 & 60.70 \\
\hline
\end{tabular}


improve our understanding of the determinants of health, for the efficient allocation of resources, and health care planning and policymaking. Our findings indicate that there is an impressive gain in LE in Oman over the last few decades which reach 76 years for both sexes in recent times. Women have been found to have a higher LE than men (79 years among women versus 74 years among men), a trend that is consistent with the trend observed around the world [27, 28]. Higher LE among women than men relates to genetics, inherent biological superiority of women over men, behavioral differences between men and women, less involvement with risk full job among women and lower risk of accidental death among women than men, and so on [29, 30]. The overall gain in LE in Oman can be attributed to the reduction of mortality and morbidity, and improvement in treatment and health care system.

It has also been observed that since 2010, LE has been stalled in the vicinity of 76 years. Further research is needed to determine the underlying causes of LE stall in Oman in recent years. A slowing increase in LE or stall in LE has also been observed in many developed and developing countries [31-35]. Even in the USA, LE has been seen a slightly decline in recent times [36]. The stall in LE in Oman might have a relation with the recent growth of non-communicable diseases such as diabetes, cardiovascular diseases, and hypertension [37] as well as disability caused by age-related changes in physical health, including mobility and ability to perform activities of daily living and road traffic accident [38, 39].

It was observed that an Omani adult of age 20 can expect to live on average 44 more years in a healthy state. As at the age of 20 years, LE is 58 years and HLE is 44 years, so the adults of age 20 years would spend on average 14 years in a poor health state or nearly one-fourth (24\%) of their total LE would spend in a poor health state. In a similar study in Brazil, using the 2003 World Health Survey (WHS) data, Romero et al. [40] observed that for Brazilian of age 20 years LE was 54 years and HLE was 47 years, indicating a longer healthy life among Brazilian than Omanis. This difference is mainly due to a higher rate of self-reported poor health status in all age groups among the Omani population than Brazilian.

Although females have longer LE than males, they have shorter HLE than males in Oman, indicating the paradox of less mortality but higher morbidity among females in Oman. This is consistent with the higher prevalence of poor health status among females than males as depicted in Figure 2. At age 20 the gap between male-female LE was found to be 4.7 years in favor of females, whereas the gap between malefemale HLE was found to be 5.8 years in favor of males. Females spent a relatively long time in poor health status than males (20.8 years versus 10.8 years) and the proportion of life spent in poor health was greater for females than males $(35.0 \%$ for females compared with $19.3 \%$ for males) (Table 4). This means that the majority of the extra years of life that females had over males were spent in poor health, demonstrating the "failure of success" [7]. Similar findings were reported by many previous studies [22, $41,42]$. Despite the empirical evidence of higher longevity among women than men across the world, in many settings, women are more disposed to morbidity, disability, depression, discrimination, and sufferings from the loneliness which may lead to the Failure of Success.

More research is needed to investigate the biological, behavioral, and social mechanisms that make gender differences in LE and HLE, so that effort can be taken to promote longevity of men and compression of disability and poor health in the years lived, especially among women.

\section{CONCLUSION}

There is an impressive gain in LE in Oman over the last few decades which reach 76 years for both sexes in recent time. Women have been found to have a higher LE than men (79 years versus 74 years). However, since 2010 LE has been stalled in the vicinity of 76 years in Oman. Further research is needed to identify the causes for the recent stall of LE in Oman. Despite higher LE among women than men, they have relatively shorter HLE, which means women are more likely to spend their extended life in poor health compared to men. This reveals the paradox of less mortality but higher morbidity among women in Oman and our result also supports the "Failure of Success" hypothesis. Considering the importance of LE and HLE as the summary measure of health outcomes, Oman should adopt a consistent measure and reporting of LE and HLE as the principal health outcome measure for the nation and regions, and adopt the policy to reduce the gender gap in LE and HLE.

\section{REFERENCES}

[1] Omran A. The epidemiologic transition: A theory of the epidemiology of population change. Milbank Mem Fund Q 1971; 49: 509-538.

https://doi.org/10.2307/3349375 
[2] Gage TB. Are Modern Environments Really Bad for Us?: Revisiting the Demographic and Epidemiologic Transitions. Am J Phys Anthropol 2005; Suppl 41: 96-117. https://doi.org/10.1002/ajpa.20353

[3] Bastian B, Tejada Vera B, Arias E, et al. Mortality trends in the United States, 1900-2018. National Center for Health Statistics. $2020 . \quad$ https://www.cdc.gov/nchs/datavisualization/mortality-trends/index.htm

[4] Olshansky SJ, Passaro DJ, Hershow RC, Layden J, Carnes BA, Brody J, Hayflick L, Butler RN, Allison DB, Ludwig DS. A potential decline in life expectancy in the United States inthe 21st Century. New Engl J Med 2005; 352(11): 1138-1145. https://doi.org/10.1056/NEJMsr043743

[5] Olshansky SJ, Carnes BA. The Future of Human Longevity. In: Peter Uhlenberg (ed) International Handbook of Population Aging, Springer, NY, 2009; pp. 731-745. https://doi.org/10.1007/978-1-4020-8356-3_33

[6] Molla MT, Wagener DK, Madans JH. Summary measures of population health: Methods for calculating healthy life expectancy. Healthy People 2010 Stat Notes 2001; (21): 111.

\section{https://doi.org/10.1037/e583762012-001}

[7] Gruenberg EM. The failures of success. Milbank Q 2005; 83(4): 779-800.

https://doi.org/10.1111/j.1468-0009.2005.00400.x

[8] Kramer M. The rising pandemic of mental disorders and associated chronic diseases and disabilities. Acta Psychiatrica Scandinavica 1980; 62(S285): 382-397. https://doi.org/10.1111/j.1600-0447.1980.tb07714.x

[9] Olshansky SJ, Rudberg MA, Carnes BA, Cassel CK, Brody JA. Trading off longer life for worsening health: the expansion of morbidity hypothesis. Journal of Aging and Health 1991; 3(2): 194-216.

https://doi.org/10.1177/089826439100300205

[10] Fries JF, Bruce B, Chakravarty E. Compression of Morbidity 1980-2011: A Focused Review of Paradigms and Progress. Journal of Aging Research 2011; 2011: 1-10. https://doi.org/10.4061/2011/261702

[11] Crimmins EM, Beltrán-Sánchez $H$. Mortality and morbidity trends: is there compression of morbidity? J Gerontol B Psychol Sci Soc Sci 2011; 66(1): 75-86. https://doi.org/10.1093/geronb/gbq088

[12] Riley JC, Alter G. The Sick and the Well: Adult Health in Britain During the Health Transition. Health Transition Review 1996; 6: 19-44.

[13] Sanders BS. Measuring community health levels. Am J Public Health Nations Health 1964; 54(7): 1063-70. https://doi.org/10.2105/AJPH.54.7.1063

[14] Sullivan DF. A single index of mortality and morbidity. Health Services and Mental Health Administration (HSMHA), Health Reports 1971; 86: 347-54.

\section{https://doi.org/10.2307/4594169}

[15] Murray CJL, Salomon JA, Mathers C. A critical examination of summary measures of population health. Bulletin of the World Health Organization, 2000; 78 (8): 981-994. World Health Organization. https://apps.who.int/iris/handle/10665/ 268203

[16] Murray CJL Lopez AD, World Health Organization, World Bank \& Harvard School of Public Health. The Global burden of disease: a comprehensive assessment of mortality and disability from diseases, injuries, and risk factors in 1990 and projected to 2020: summary / edited by Christopher JL. Murray Alan D. Lopez. World Health Organization 1996. https://apps.who.int/iris/handle/10665/41864

[17] Crimmins EM, Hayward MD, Saito Y. Changing mortality and morbidity rates and the health status and life expectancy of the older population. Demography 1994; 31: 159-175. https://doi.org/10.2307/2061913
[18] Islam MM. Demographic Transition in Sultanate of Oman: Emerging Demographic Dividend and Challenges, Middle East Fertility Society Journal 2020; 25(7): 1-14.

[19] National Centre for Statistics and Information (NCSI). Statistical Year Book 2020. Ministry of National Economy, Muscat, Oman 2021.

[20] Murray CJL, Salomon JA, Mathers CD, Lopez AD. Summary Measures of Population Health: Concepts, Ethics, Measurement and Applications, World Health Organization 2002. http://apps.who.int/bookorders/anglais/detart1.jsp?

[21] Di Lego V, Di Giulio P, Luy M. Gender Differences in Healthy and Unhealthy Life Expectancy. In: Jagger C, Crimmins E, Saito Y, De Carvalho Yokota R, Van Oyen H, Robine JM. (eds) International Handbook of Health Expectancies. International Handbooks of Population, vol 9. Springer, Cham 2020.

https://doi.org/10.1007/978-3-030-37668-0_11

[22] Alam MZ. Women outweighed men at life expectancy in Bangladesh: does it mean a better quality of life? Heliyon 2021; 7: e07618. https://doi.org/10.1016/j.heliyon.2021.e07618

[23] Al Riyami A, Elaty MA, Morsi M, Al Kharusi H, Al Shukaily W, Jaju S. Oman World Health Survey: Part 1 - Methodology, Sociodemographic Profile and Epidemiology of NonCommunicable Diseases in Oman. Oman Medical Journal 2012; 27(5): 425-443. https://www.omjournal.org/images/ 298_M_Deatials_Pdf_.pdf

[24] Chiang CL. The life table and its applications. R.E. Krieger Publishing Company, Malabar, Florida, USA 1984.

[25] National Centre for Statistics and Information (NCSI). Statistics Year-Book 2020, Oman, Ministry of National economy, Muscat, Oman, 2021. Available at http://www.ncsi.gov.om.

[26] United Nations, Department of Economic and Social Affairs, Population Division (2019) World Population Prospects: The 2019 Revision, custom data acquired via website. Available at http://www.population.un.org/wpp.

[27] United Nations, Department of Economic and Social Affairs. World Population Ageing 2007. New York, NY: United Nations Publication; 2007. https://www.un.org/en/ development/desa/population/publications/pdf/ageing/WorldP opulationAgeingReport2007.pdf

[28] World Health Organization Statistical Information System (WHOSIS). World Health Organization statistical information database. http://www.who.int/whosis/en/.

[29] World Health Organization (WHO) Global Health Observatory (GHO); 2020. Female Life Expectancy. https://www.who.int/ gho/women_and_health/mortality/situation_trends_life_expec tancy/en/

[30] Seifarth JE, McGowan CL, Milne KJ. Sex and life expectancy. Gend Med 2012; 9(6): 390-401.

https://doi.org/10.1016/j.genm.2012.10.001

[31] Leon DA, Jdanov DA, Shkolnikov VM. Trends in life expectancy and age-specific mortality in England and Wales, 19702016, in comparison with a set of 22 highincome countries: an analysis of vital statistics data. Lancet Public Health 2019; 4: e575-82. https://doi.org/10.1016/S2468-2667(19)30177-X

[32] Raleigh VS. Trends in life expectancy in EU and other OECD countries. OECD Health Working Papers.

[33] Debon A, Chaves L, Haberman S, Villa F. Characterization of between-group inequality of longevity in European Union countries. Insur: Math Econ 2017; 75: 151-65. https://doi.org/10.1016/j.insmatheco.2017.05.005

[34] Fenton L, Minton J, Ramsay J, et al. Recent adverse mortality trends in Scotland: comparison with other highincome countries. BMJ Open 2019; 9: 1-9. https://doi.org/10.1136/bmjopen-2019-029936 
[35] Lopez AD, Adair T. Slower increase in life expectancy in Australia than in other high income countries: the contributions of age and cause of death. Med J Aust 2019; 210: 403-9.

https://doi.org/10.5694/mja2.50144

[36] Venkataramani AS, O'Brien R, Tsai AC. Declining Life Expectancy in the United States: The Need for Social Policy as Health Policy. JAMA 2021; 325(7): 621-622. https://doi.org/10.1001/jama.2020.26339

[37] Waxman A, Norum KR. Why a global strategy on diet, physical activity and health? The growing burden of noncommunicable diseases. Public Health Nutr 2007; 7: 381383.

https://doi.org/10.1079/PHN2004623

[38] Islam MM, Ahmed, Al-Hadhrami. Increased Motorization and Road Traffic Accidents in Oman. Journal of Emerging Trends in Economics and Management Science 2012; 3(6): 907914. https://maqsurah.com/uploads/items/57670/files/FULL/ 2020-08-17_09_20_365458364.pdf

[39] Islam MM, Al Hadhrami AY, Rashid M. Self-rated health status, functional difficulties in health domains and non- communicable diseases in Oman: evidence from the World Health Survey in Oman. International Research Journal of Public and Environmental Health 2021; 8(1): 8-19.

[40] Dalia Romero D, da Costa Leite I, Szwarcwald CL. Healthy life expectancy in Brazil: applying the Sullivan method. Cadernos de saúde pública / Ministério da Saúde, Fundação Oswaldo Cruz, Escola Nacional de Saúde Pública 21 Suppl(suppl 1) 2005; 21: 7-18. https://doi.org/10.1590/S0102-311X2005000700002

[41] Arber S, Cooper H. Gender differences in health in later life: the new paradox? Social Science \& Medicine 1999; 48: 6176.

https://doi.org/10.1016/S0277-9536(98)00289-5

[42] Lau RS, Johnson S, Kamalanabhan TJ. Healthy Life Expectancy in the Context of Population Health and Ageing in India. Asia-Pacific Journal of Public Health 2012; 24(1): 195-207. https://doi.org/10.1177/1010539510376663

[43] Hinde A. Demographic Methods. Taylor and Francise, London, 2014.

Received on 01-10-2021

https://doi.org/10.6000/1929-6029.2021.10.13

(C) 2021 M. Mazharul Islam; Licensee Lifescience Global.

This is an open access article licensed under the terms of the Creative Commons Attribution License (http://creativecommons.org/licenses/by/4.0/) which permits unrestricted use, distribution and reproduction in any medium, provided the work is properly cited. 